\section{Evaluation of Chilling and Heat Requirements in Japanese Apricot with Three Models}

\author{
Zhihong Gao ${ }^{1}$, Weibing Zhuang ${ }^{1}$, Liangju Wang, Jing Shao, \\ Xiaoyan Luo, Binhua Cai, and Zhen Zhang ${ }^{2}$ \\ College of Horticulture, Nanjing Agricultural University, No. 1 Weigang, \\ Nanjing 210095, P.R. China
}

Additional index words. chilling accumulation, dormancy, dynamic model, flowering, Prunus mume, Utah model, Weinberger model

\begin{abstract}
Estimating chilling requirements is crucial for identifying appropriate cultivars for a given site, for timing applications of dormancy-breaking chemical agents, and for predicting consequences of climate change. For temperate-zone fruit species such as japanese apricot, productivity is reduced when chilling requirements are not adequately satisfied. In our study, we obtained chilling and heat requirements for flowering of six japanese apricot cultivars, which spanned the range of flowering times in this species for three successive years. Different methods for determining chilling requirements were evaluated and compared, and correlations among chilling requirements, heat requirements, and flowering date were established. The dynamic model proved to be the best for determining the chilling requirements of japanese apricot. The results showed a range of chilling requirements ranging from 26.3 to 75.7 chill portions and a narrow range of heat requirements, from 1017.7 to 1697.3 growing degree-hours (GDH). A very high correlation $(R=0.9797)$ between flowering date and chilling requirements and a low correlation $(R=0.4298)$ between flowering date and heat requirements suggest that flowering date in japanese apricot is mainly a consequence of the chilling requirements of the different genotypes, whereas heat requirements contribute a limited effect to the variation in flowering dates. Chilling requirements and heat requirements were positively related with a low correlation coefficient $(R=0.4211)$.
\end{abstract}

Japanese apricot (Prunus mume Sieb. et Zucc.) originated in China and has been widely cultivated in Asia for $\approx 3000$ years (Chu, 1999). Owing to its charming flowers and flavorsome fruit, it has been widely planted as an ornamental plant and an economic fruit tree; its fruit is consumed as a preserve and a drink in China (Shi et al., 2009). The cultivars of japanese apricot in Taiwan have the lowest chilling requirements in the world (Ou and Chen, 2003). Owing to being greatly restricted by climatic conditions, especially related to chilling accumulation, the

Received for publication 13 June 2012. Accepted for publication 24 Sept. 2012.

We gratefully acknowledge the 2012 Jiangsu Province scientific research and innovation projects of postgraduates (CXZZ12 0283), the Natural Science Foundation of Jiangsu Province (BK2011642) for providing financial support, and the National Science Foundation of China (31101526) and the Priority Academic Program Development of Jiangsu Higher Education Institutions (PAPD) for funding part of this study. We greatly appreciate the help of Rebecca Darbyshire (University of Melbourne), who made the procedure commonly used for calculating chill portions according to the dynamic model available for our study.

${ }^{1}$ These authors contributed equally to the article, and in their opinion, the first two authors should be regarded as joint first authors.

${ }^{2}$ To whom reprint requests should be addressed; e-mail zhangzh@njau.edu.cn. distribution of japanese apricot is limited to East Asia, including China, Japan, and Korea; it is rarely cultivated in other countries $(\mathrm{Ou}$ and Chen, 2003). Therefore, we studied the chilling and heat requirements of japanese apricot to help producers breed new cultivars and to assist horticulturists in other countries to introduce the appropriate cultivars.

The study of the phenological behavior of crops, as part of a well-characterized environment, is important both to obtain satisfactory production and to determine the most suitable agronomic techniques (Valentini et al., 2001). Many fruit and nut crops require chilling accumulation in winter to break dormancy. Quantifying this chilling requirement and selecting appropriate cultivars for the climate of a given region are crucial for successful cultivation of such crops. If the chilling requirement is not satisfied, budbreak will be uneven and delayed, shoot vigor will be reduced, and flower development will be poor (Campbell and Sugano, 1975). On the other hand, in the case of low chilling requirements (e.g., early-flowering cultivars growing in coldwinter areas), blooming happens too early and freezes can reduce yield (Bartolini et al., 2006). The information of the chilling requirement of a cultivar has significant practical and economic impacts on the control, maintenance, and production of woody plants (Fennell, 1999) and is necessary for crop management of japanese apricot cultivars in their most suitable areas.
To better quantify winter chilling accumulation, past researchers have developed several chilling models. Temperature has been described as the most decisive climatic factor. The Weinberger model (Weinberger, 1950), still widely used, is the oldest method to quantify winter chilling accumulation. The Utah model (Richardson et al., 1974), which is most widely used, contains a weight function assigning different chilling efficiencies to different temperature ranges, including negative contributions by high temperatures. The dynamic model (Fishman et al., 1987a, 1987b), which overcomes some difficulties of the Utah model, especially in mild-winter climates, postulates that winter chilling accumulates in a two-step process. Initially, cold temperatures lead to the formation of an intermediate product. Once a certain quantity of this intermediate has accumulated, it can be transformed into a "chill portion." In this age of global warming, many researchers have tested which chilling model is best in different regions of the world (Luedeling, 2009a, 2009b, 2009c, 2011; Rahemi and Pakkish, 2009).

The difficulty that a number of deciduous fruit trees have in adapting to environmental conditions different from those of their origin is well known and is mainly the result of the need for adequate satisfaction of their chilling requirements for flowering. Problems related to the inaccurate selection of cultivars with unsuitable chilling requirements affect japanese apricot production. Many growers used winter chilling accumulation to determine the timeline for certain management measures, such as the spraying of rest-breaking chemical agents, or to predict yield potential (Erez, 2000).

Once the chilling requirements have been satisfied, heat is required for full bloom. However, studies on heat requirements are fewer and the effects of heat requirements on flowering date are less known (Citadin et al., 2001; Couvillon and Erez, 1985; Gariglio et al., 2006). Methods of determining the heat requirements for flowering have been developed (Anderson et al., 1986; Richardson et al., 1974). It is still not clear what the relation is between heat requirements and chilling requirements for flowering.

It is imperative that the chilling requirements of japanese apricot should be determined to prevent the future planting of cultivars that will not perform well under the predicted climate change scenarios. Some researchers used different methods to determine the chilling requirements of japanese apricot (Ou and Chen, 2003; Wang et al., 2007; Yamane et al., 2006). Up to now, unfortunately, no systematic calculation of chilling requirement has been developed for japanese apricot cultivars and new selections.

The purpose of our study was the calculation of the chilling and heat requirements for flowering of japanese apricot cultivars during the full range of flowering time in three successive years. We also evaluated and compared different methods for determining chilling requirements and established correlations 
Table 1. Chilling accumulation under field conditions according to the Utah model, dynamic model, and Weinberger model. ${ }^{\mathrm{z}}$

\begin{tabular}{|c|c|c|c|c|c|}
\hline Yr & 30 Nov. & 31 Dec. & 31 Jan. & 28 Feb. & 15 Mar \\
\hline \multicolumn{6}{|c|}{ Chill units (Utah model) } \\
\hline $2009-10$ & 286 & 727 & 1068 & 1389 & 1585 \\
\hline $2010-11$ & 203 & 482 & 693 & 1002 & 1150 \\
\hline $2011-12$ & -46 & 320 & 786 & 1224 & 1448 \\
\hline Mean & 147 & 509 & 849 & 1205 & 1394 \\
\hline SD & 174 & 205 & 195 & 194 & 222 \\
\hline CV $(\%)$ & 118 & 40 & 23 & 16 & 16 \\
\hline \multicolumn{6}{|c|}{ Hours (Weinberger model) } \\
\hline 2009-10 & 318 & 634 & 1004 & 1322 & 1537 \\
\hline $2010-11$ & 203 & 497 & 811 & 1150 & 1350 \\
\hline $2011-12$ & 103 & 417 & 883 & 1354 & 1565 \\
\hline Mean & 208 & 516 & 899 & 1275 & 1484 \\
\hline SD & 108 & 110 & 98 & 110 & 117 \\
\hline CV $(\%)$ & 52 & 21 & 11 & 9 & 8 \\
\hline \multicolumn{6}{|c|}{ Portions (dynamic model) } \\
\hline 2009-10 & 16 & 40 & 62 & 80 & 91 \\
\hline 2010-11 & 10 & 30 & 50 & 69 & 78 \\
\hline $2011-12$ & 7 & 29 & 51 & 72 & 82 \\
\hline Mean & 11 & 33 & 54 & 74 & 84 \\
\hline SD & 5 & 6 & 7 & 6 & 7 \\
\hline CV $(\%)$ & 42 & 19 & 12 & 8 & 8 \\
\hline
\end{tabular}

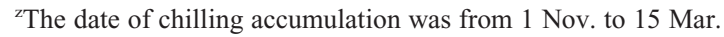

among chilling requirements, heat requirements, and flowering date. This information can be used to advise japanese apricot farmers about the cultivars best suited to their area and which areas are the most appropriate for production.

\section{Materials and Methods}

Plant materials. The plant material comprised six japanese apricot cultivars spanning the full range of flowering time. The early flowering cultivars were 'Taoxingmei' and 'Shuangshuidaroumei', the late flowering cultivars Fenghou and Yanhua, and the medium flowering cultivars Dongqing and Xiyeqing. All the cultivars were grown in the National Field Genebank for japanese apricot (altitude $10 \mathrm{~m}$, lat. $32^{\circ} 03^{\prime} \mathrm{N}$, long. $118^{\circ} 46^{\prime}$ E) located in Nanjing, Jiangsu Province, China. The trees were eight years old at the beginning of the study, and all trees received similar cultural practices such as irrigation and fertilization.

Sample collection. The experiments were conducted in three consecutive years (200912 ) in the experimental orchard of the $\mathrm{Na}$ tional Field Genebank for japanese apricot (Nanjing, China). Hourly temperatures were collected from November to April by a thermohygrograph and an automatic data logger (Hangzhouzeda Instrument Co., Ltd., Hangzhou, China).

From the beginning of the chilling accumulation, five branches of each cultivar (with lengths of $\approx 25 \mathrm{~cm}$ and diameter of $5 \mathrm{~mm}$ ) were collected weekly from trees in the orchard and the bases were placed in a $5 \%$ sucrose solution in a growth chamber, making a fresh cut at the base of the branches. The branches were maintained at $25 \pm 1{ }^{\circ} \mathrm{C}$ under white fluorescent tubes $\left(55 \mu \mathrm{mol} \cdot \mathrm{m}^{-2} \cdot \mathrm{s}^{-1}\right)$ during a photoperiod of $16 \mathrm{~h}$ and at $18 \pm 1{ }^{\circ} \mathrm{C}$ during the dark period of $8 \mathrm{~h}$ with a constant relative humidity of $70 \%$. The sucrose solution was refreshed and bases cut every $3 \mathrm{~d}$. The development stage of the flower buds was recorded after $10 \mathrm{~d}$ in the growth chamber.

Determination of chilling and heat requirements. The start date for chilling accumulation was considered to be when a consistent chilling accumulation occurred and the temperatures producing a negative effect (chilling negation) (Erez et al., 1979; Guerriero et al., 2002; Richardson et al., 1974) were rare. Both physical and physiological parameters were used to determine the date of breaking of dormancy (Campoy et al., 2010, 2012; Guerriero et al., 2002; Ruiz et al., 2007). From the sampled branches, three replicates of 20 flower buds were sampled before and after forcing. The date of breaking of endodormancy was established when, after $10 \mathrm{~d}$ in the growth chamber, $30 \%$ of the flower buds were in Baggiolini's stage B to C (green tip) (Baggiolini, 1952), and there was at least an average 30\% increase in bud weight. The chilling requirements coincided with the chilling accumulated until the date of dormancy release. Determination of chilling requirements was by hours between 0 and $7.2^{\circ} \mathrm{C}$ for the Weinberger model (Weinberger, 1950), chill units for the Utah model (Richardson et al., 1974), and chill portions for the dynamic model (Fishman et al., 1987a, 1987b).

The equations for the Weinberger model are as follows (Weinberger, 1950):

$$
\begin{aligned}
\mathrm{CH}_{\mathrm{t}}= & \sum_{\mathrm{i}=1}^{\mathrm{t}} \mathrm{T}_{7.2}, \text { with } \\
\mathrm{T}_{7.2} & = \begin{cases}0^{\circ} \mathrm{C}<\mathrm{T}<7.2^{\circ} \mathrm{C} & : 1 \\
\text { else } & : 0\end{cases}
\end{aligned}
$$

The equations for the Utah model are as follows (Richardson et al., 1974):

$$
\begin{aligned}
\operatorname{Utah}_{\mathrm{t}} & =\sum_{\mathrm{i}=1}^{\mathrm{t}} \mathrm{T}_{\mathrm{u}} \text {, with } \\
\mathrm{T}_{\mathrm{u}} & = \begin{cases}\mathrm{T} \leq 1.4^{\circ} \mathrm{C} & : 0 \\
1.4^{\circ} \mathrm{C}<\mathrm{T} \leq 2.4^{\circ} \mathrm{C} & : 0.5 \\
2.4^{\circ} \mathrm{C}<\mathrm{T} \leq 9.1^{\circ} \mathrm{C} & : 1 \\
9.1^{\circ} \mathrm{C}<\mathrm{T} \leq 12.4^{\circ} \mathrm{C} & : 0.5 \\
12.4^{\circ} \mathrm{C}<\mathrm{T} \leq 15.9^{\circ} \mathrm{C} & : 0 \\
15.9^{\circ} \mathrm{C}<\mathrm{T} \leq 18.0^{\circ} \mathrm{C} & :-0.5 \\
\mathrm{~T}>18.0^{\circ} \mathrm{C} & :-1\end{cases}
\end{aligned}
$$

The equations for the dynamic model are as follows (Darbyshire et al., 2011; Fishman et al., 1987a, 1987b):

$$
\begin{aligned}
& \mathrm{x}_{\mathrm{i}}=\frac{\mathrm{e}^{\mathrm{slp} \cdot \mathrm{tetm} \mathrm{lt} \cdot \frac{\mathrm{Tk}-\mathrm{tetm} \mathrm{lt}}{\mathrm{Tk}}}}{1+\mathrm{e}^{\mathrm{slp} \cdot \operatorname{tetm} \mathrm{lt} \cdot \frac{\mathrm{Tk}-\mathrm{tetm} \mathrm{lt}}{\mathrm{Tk}}}} \\
& \mathrm{x}_{\mathrm{S}}=\frac{\mathrm{a}_{0}}{\mathrm{a}_{1}} \cdot \mathrm{e}^{\frac{\mathrm{e} 1-\mathrm{e} 0}{\mathrm{Tk}}} \\
& \mathrm{ak}_{1}=\mathrm{a}_{1} \cdot \mathrm{e}^{-\frac{\mathrm{e} 1}{\mathrm{Tk}}} \\
& \text { int } \mathrm{er}_{\mathrm{E}}=\mathrm{x}_{\mathrm{s}}-\left(\mathrm{x}_{\mathrm{s}}-\text { int } \mathrm{er}_{\mathrm{s}}\right) \cdot \mathrm{e}^{-\mathrm{ak}} \\
& \text { int } \mathrm{er}_{\mathrm{s}}=
\end{aligned}
$$

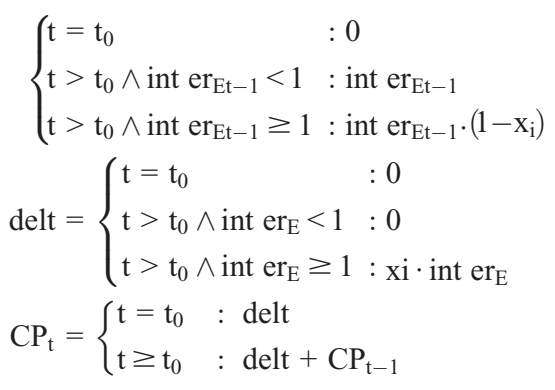

Accordingly, the constants $\mathrm{a}_{0}, \mathrm{a}_{1}, \mathrm{e}_{0}, \mathrm{e}_{1}$, slp, and tetml were set to $1.395 \times 10^{5}, 2.567 \times$ $10^{18}, 4,153.5,12,888.8,1.6$, and 277 , respectively. $T_{K}$ is the measured hourly temperature in Kelvin, whereas $t$ denotes the time during the season (in hours) with $\mathrm{t}_{0}$ being the starting point of chilling accumulation.

Heat requirements were calculated as GDH following the model proposed by Richardson et al. (1974). GDHs are hourly average temperatures $\left({ }^{\circ} \mathrm{C}\right)$ minus $4.5{ }^{\circ} \mathrm{C}$, which are accumulated daily. For each cultivar, heat requirements were calculated as the number of GDH accumulated between the end of dormancy and the date when $50 \%$ of flowers were open $\left(\mathrm{F}_{50}\right)$ in the orchard. The length of this period was expressed as the increment of Julian days (delta JD). We determined delta JD as a complement for GDH, because delta JD is highly dependent on the temperature conditions of the area and year.

Statistical analysis. Statistical analyses were performed using SPSS 17.0 for Windows (SPSS Inc., Chicago, IL) and Duncan's multiple range test. Correlation coefficients were determined as Pearson's coefficients. The differences between groups were determined by Tukey's b test $(P<$ $0.01)$. The $\operatorname{cvs}(\sigma / \mu \times 100)$ were calculated to assess the variability of chilling requirement among cultivars and years using the different models. 


\section{Results}

Chilling accumulation under field conditions. Under field conditions, chilling accumulation during November was rather low; in 2011-12, it had a negative value as measured by the Utah model (Table 1). The most efficient months for chilling accumulation were from December through February, although the first fortnight of March also contributed considerably in some years (Table 1). The lowest chilling accumulation in March was registered in 2010-11 with 1150 chill units compared with 1584.5 in $2009-10$ and 1447.5 in 2011-12.

Data among years were more homogeneous with the dynamic and Weinberger models than with the Utah model. Variability was very high with the Utah model. CV for chilling accumulation until 15 Mar. was $15.9 \%$ with the Utah model, $8.0 \%$ with the dynamic model, and $7.9 \%$ in the case of the Weinberger model.

Chilling requirements for breaking of dormancy. Differences in bud weight on cuttings were evident between cultivars, and the

\section{9-2010}

\section{0}

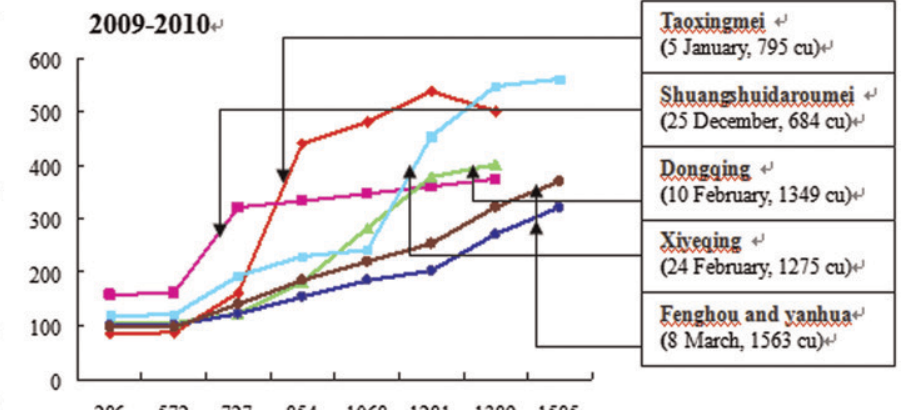

$\begin{array}{llllllll}286 & 572 & 727 & 854 & 1068 & 1281 & 1389 & 1585\end{array}$

Chill units (Utah model)

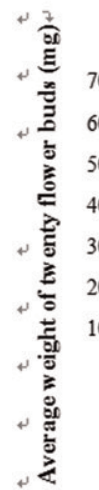

2010-2011

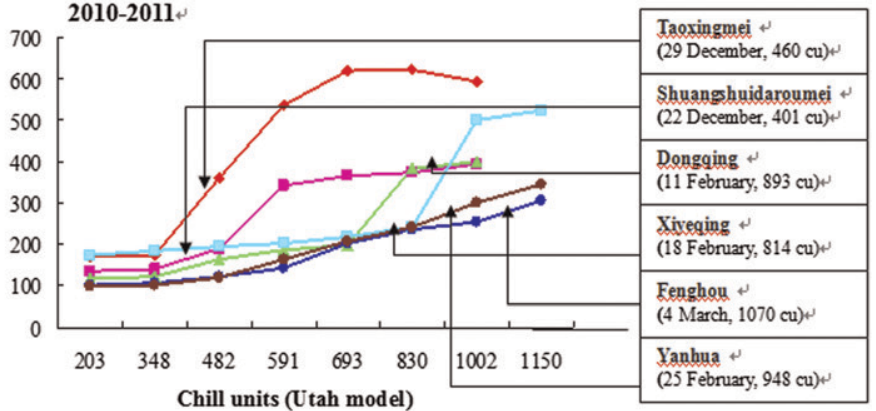



2011-2012

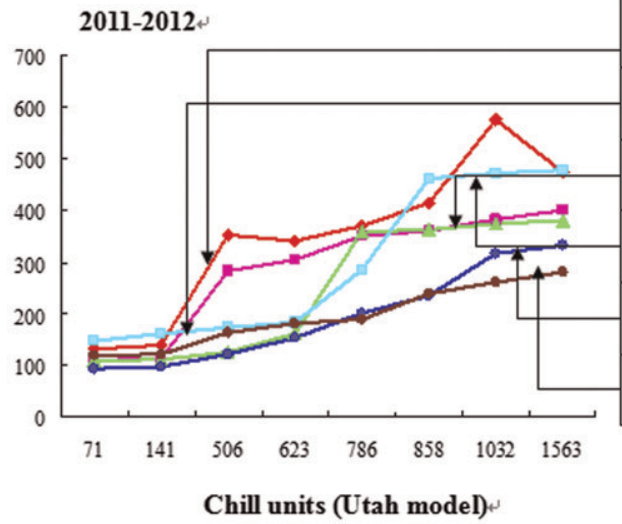

$\begin{array}{ll}- \text { Taoxingmei } & \rightarrow \text {-Shuangshuidarounei } \\ - \text {-Xiveqing } & \rightarrow \text { Dongqing }\end{array}$

Fig. 1. Increase in weight of the flower buds on excised cuttings with chilling accumulation in six japanese apricot cultivars in three successive years. Vertical axis represents average weight of 20 flower buds, which indicate the bud development, and horizontal axis represents chilling requirement measured by the Utah model. end of dormancy was sharper in some cultivars than in others (Fig. 1). Bud weight of 'Fenghou' and 'Yanhua' did not increase as much as that of the other four cultivars despite considerable chilling accumulation, probably because they did not accumulate enough chilling requirements that year or because few flower buds were present.

The cultivars showed a wide range of chilling requirements for flowering from 26.3 to 75.7 chill portions (Table 2). 'Taoxingmei' and 'Shuangshuidaroumei' completed dormancy on accumulation of 32 and 26.3 chill portions, respectively, and were classified as low-chilling cultivars. The chilling requirements of 'Dongqing' and 'Xiyeqing' were intermediate with 57.7 and 64 chill portions. 'Fenghou' and 'Yanhua' showed high chilling requirements with values of 72.7 and 75.7 chill portions. The $\mathrm{CV}$ of the chilling requirements for blooming for all of the evaluated cultivars considered together was very different depending on the method; the CV was $27.1 \%$ with the Utah model, $16.5 \%$ with the dynamic model, and $23 \%$ with the Weinberger model. The $\mathrm{CV}$ among years differed significantly, 'Shuangshuidaroumei' having the highest (25.9).

Our results indicate a high positive correlation between chilling requirements and flowering date and between chilling requirements and date of dormancy breaking with a correlation coefficient close to $R=0.98$, respectively, in the three models of chilling estimation (Table 3). There was a negative correlation between chilling requirements and delta JD.

Heat requirements for flowering. The mean heat requirements for the cultivars ranged from 1017.7 to $1697.3 \mathrm{GDH}$. Some cultivars, Shuangshuidaroumei and Fenghou, showed similar values in the three years, whereas important differences were observed in other cultivars (Table 4). No significant differences in the heat requirements were found among cultivars with strong differences in $\mathrm{F}_{50}$ (Table 4). However, significant differences were found among cultivars as well as among years with regard to the delta JD. The mean values of the delta JD ranged from 15.7 in 'Yanhua' to 47.7 in 'Shuangshuidaroumei'. The low chilling cultivar Shuangshuidaroumei showed the highest delta JD, whereas the high chilling cultivar Yanhua showed the lowest delta JD. In 'Taoxingmei' and 'Shuangshuidaroumei', the results were practically the same over the three years. In contrast, 'Xiyeqing' and 'Yanhua' showed very different delta JD values in different years (Table 4).

The relationship between chilling requirements for breaking of dormancy and heat requirements for flowering was positive (Table 3 ) and the correlation coefficient was not very high $(R=0.4211)$. The highest correlation coefficient was obtained in the case of chill portions (dynamic model). The correlation coefficients were higher when delta JD and chilling requirement values were analyzed, and they ranged from $R=-0.8092$ in hours among 0 to $7.2{ }^{\circ} \mathrm{C}$ to 
Table 2. Chilling requirements for flowering of the japanese apricot cultivars determined by three models (Weinberger model, Utah model, and dynamic model).

\begin{tabular}{|c|c|c|c|c|c|c|c|c|c|c|c|c|c|c|}
\hline \multirow[b]{2}{*}{ Cultivar } & \multirow[b]{2}{*}{$\mathrm{Yr}$} & \multirow{2}{*}{$\begin{array}{c}\text { Date of } \\
\text { breaking } \\
\text { dormancy }\end{array}$} & \multicolumn{4}{|c|}{ Chill units (Utah model) } & \multicolumn{4}{|c|}{ Hours (Weinberger model) } & \multicolumn{4}{|c|}{ Chill portions (dynamic model) } \\
\hline & & & Value & Mean & SD & CV $(\%)$ & Value & Mean & SD & CV (\%) & Value & Mean & SD & CV $(\%)$ \\
\hline \multirow{2}{*}{ Taoxingmei } & $2009-10$ & 5 Jan. & 795 & & & & 443 & & & & 41 & & & \\
\hline & $2010-11$ & 29 Dec. & 460 & $567 \mathrm{a}^{\mathrm{z}}$ & 198 & 35 & 224 & $332 \mathrm{a}$ & 110 & 33 & 29 & $32 \mathrm{a}$ & 8 & 25 \\
\hline \multirow{3}{*}{ Shuangshuidaroumei } & 2009-10 & 25 Dec. & 684 & & & & 315 & & & & 34 & & & \\
\hline & $2010-11$ & 22 Dec. & 401 & $479 a$ & 180 & 38 & 149 & $239 a$ & 84 & 35 & 24 & $26 \mathrm{a}$ & 7 & 26 \\
\hline & $2011-12$ & 23 Dec. & 352 & & & & 252 & & & & 21 & & & \\
\hline \multirow{3}{*}{ Xiyeqing } & 2009-10 & $24 \mathrm{Feb}$. & 1275 & & & & 891 & & & & 74 & & & \\
\hline & 2010-11 & $18 \mathrm{Feb}$. & 814 & $1040 \mathrm{ab}$ & 231 & 22 & 668 & $828 \mathrm{~b}$ & 139 & 17 & 62 & $64 \mathrm{~b}$ & 9 & 14 \\
\hline & $2011-12$ & $5 \mathrm{Feb}$ & 1031 & & & & 924 & & & & 56 & & & \\
\hline \multirow[t]{3}{*}{ Fenghou } & $2009-10$ & 8 Mar. & 1563 & & & & 1230 & & & & 82 & & & \\
\hline & $2010-11$ & 4 Mar. & 1070 & $1323 \mathrm{~b}$ & 247 & 19 & 959 & $1148 \mathrm{~b}$ & 162 & 14 & 67 & $73 \mathrm{~b}$ & 8 & 11 \\
\hline & $2011-12$ & $28 \mathrm{Feb}$. & 1336 & & & & 1248 & & & & 69 & & & \\
\hline
\end{tabular}

${ }^{2}$ Within columns, means followed by the same letter do not differ significantly at the $5 \%$ level, according to Duncan's multiple range test.

Table 3. Correlations between various factors related to the breaking of dormancy and time of flowering in japanese apricot.

\begin{tabular}{llc}
\hline Factor & \multicolumn{1}{c}{ Variables correlated } & Correlation coefficient $(R)^{2}$ \\
\hline delta JD & GDH & -0.4887 \\
delta JD & Chill units & -0.8107 \\
delta JD & Portions & -0.9414 \\
delta JD & Hours between $0-7.2{ }^{\circ} \mathrm{C}$ & -0.8092 \\
delta JD & $\mathrm{F}_{50}$ & -0.8928 \\
delta JD & Date of dormancy breaking & -0.9667 \\
GDH & Chill units & 0.3348 \\
GDH & Portions & 0.4211 \\
GDH & Hours between 0-7.2 ${ }^{\circ} \mathrm{C}$ & 0.2995 \\
GDH & $\mathrm{F}_{50}$ & 0.4298 \\
GDH & Date of dormancy breaking & 0.4331 \\
Chill units & $\mathrm{F}_{50}$ & 0.9788 \\
Chill units & Date of dormancy breaking & 0.9821 \\
Portions & $\mathrm{F}_{50}$ & 0.9797 \\
Portions & Date of dormancy breaking & 0.9909 \\
Hours between $0-7.2{ }^{\circ} \mathrm{C}$ & $\mathrm{F}_{50}$ & 0.9806 \\
Hours between $0-7.2{ }^{\circ} \mathrm{C}$ & Date of dormancy breaking & 0.9783 \\
$\mathrm{~F}_{50}$ & Date of dormancy breaking & 0.9741 \\
\hline R & &
\end{tabular}

${ }^{\mathrm{z}} R=$ correlation coefficient

${ }^{\mathrm{y}}$ The length of the period from the breaking of dormancy to the $\mathrm{F}_{50}(50 \%$ of opened flowers) date in the experimental orchard.

$\mathrm{JD}=$ Julian days.

$R=-0.9414$ in chill portions. There was a limited correlation between heat requirements and the flowering date.

Flowering date. Flowering dates differed among cultivars (Table 4). The earliestflowering cultivar was 'Shuangshuidaroumei', which flowered between 5 Feb. and 10 Feb., although differences were observed between years. 'Shuangshuidaroumei' flowered $42 \mathrm{~d}$ earlier than 'Fenghou'. 'Dongqing' and 'Xiyeqing' were classified as middle-flowering, because their flowering date was around mid-March. The latest-flowering cultivars were 'Fenghou' and 'Yanhua' with flowering date on 28 Mar. and therefore these cultivars may be useful for regions subject to freezes.

All the chilling requirement models had high correlation coefficients with flowering date in three consecutive years (Table 3), which indicated that chilling requirement played an important role in the flowering of japanese apricot. A limited correlation coefficient between flowering date and heat requirement was observed (Table 3 ).

\section{Discussion}

Chilling accumulation in the field. In our study, the variability of chilling accumulation was very high when the Utah model was used (Table 1), which may be the result of the mild winter climate of Nanjing. Meanwhile, the high temperature registered in the late fall and early winter of 2011-2012 delayed the onset of chilling accumulation compared with the other two years (Table 1). The variability between years is similar with both the Weinberger model and dynamic model, which show lower variability than the Utah model. The dynamic model, as a result of its convincing theoretical framework and its application in both cool and warm areas, has proven to be a most appropriate method to determine the chilling requirements of deciduous fruit. Therefore, we applied the dynamic model to measure chilling requirements or total chilling accumulation for selecting the appropriate cultivar in Nanjing.

Chilling requirements for breaking of dormancy of japanese apricot cultivars. Researchers have used different methods to determine the chilling requirements of japanese apricot. Ou and Chen (2003) in Taiwan used a Taiwan low-chill model with a range of -12 to 50 chill units. Wang et al. (2007) suggested that the 0 to $14{ }^{\circ} \mathrm{C}$ model could be used as an index for estimating chilling requirements in the southern subtropical area of China with the value from $110 \mathrm{~h}$ to $180.3 \mathrm{~h}$. Yamane et al. (2006) applied the 0 to $7.2{ }^{\circ} \mathrm{C}$ model and reported that the early flowering cultivar Ellching required 300 chilling hours, whereas the midseason flowering cultivar Nanko required $500 \mathrm{~h}$. Comparing results obtained by different researchers is difficult because many factors need to be considered such as the choice of plant material, the criteria used to determine when dormancy is completed, and the environmental conditions during the previous growing season (Dennis, 2003). Another important factor is the lack of standard protocols to calculate chilling requirements, which hinders the comparison of the chilling requirements. When chilling requirements are supplemented with information on tree behavior as well as the location, conditions, and duration under which the chilling requirements were determined, they will have a broader application (Campoy et al., 2010, 2011). Some researchers began to dedicate to the conversion factors, which facilitated the comparison of chilling requirements calculated with different chilling models and different areas (Luedeling et al., 2009b).

Others researchers also reported a high correlation between chilling requirement and flowering time (Campoy et al., 2012; Ruiz et al., 2007). In agreement with our results, there is also a high correlation between chilling requirement and flowering time with 


\begin{tabular}{|c|c|c|c|c|c|c|c|c|c|c|c|}
\hline \multirow[b]{2}{*}{ Cultivar } & \multirow[b]{2}{*}{$\mathrm{Yr}$} & \multirow[b]{2}{*}{ Breaking dormancy } & \multirow[b]{2}{*}{ Flowering $\left(\mathrm{F}_{50}\right)$} & \multicolumn{4}{|c|}{ Delta JD } & \multicolumn{4}{|c|}{ GDH } \\
\hline & & & & Value & Mean $^{\mathrm{y}}$ & SD & $\mathrm{CV}(\%)$ & Value & Mean & SD & $\mathrm{CV}(\%)$ \\
\hline \multirow[t]{3}{*}{ Taoxingmei } & $2009-10$ & 5 Jan. & $12 \mathrm{Feb}$ & 38 & & & & 1332 & & & \\
\hline & $2010-11$ & 29 Dec. & 17 Feb. & 50 & $456 \mathrm{~b}$ & 6.7 & 14.7 & 992 & 1103 & 198.7 & 18 \\
\hline & $2011-12$ & 30 Dec. & 17 Feb. & 49 & & & & 983 & & & \\
\hline \multirow[t]{3}{*}{ Shuangshuidaroumei } & $2009-10$ & 25 Dec. & 5 Feb. & 42 & & & & 1269 & & & \\
\hline & $2010-11$ & 22 Dec. & 12 Feb. & 52 & $46 \mathrm{~b}$ & 5.1 & 10.7 & 1288 & 1235 & 76.6 & 6.2 \\
\hline & $2011-12$ & 23 Dec. & $10 \mathrm{Feb}$. & 49 & & & & 1147 & & & \\
\hline \multirow[t]{3}{*}{ Dongqing } & $2009-10$ & 10 Feb. & 12 Mar. & 30 & & & & 1168 & & & \\
\hline & $2010-11$ & 11 Feb. & 5 Mar. & 22 & $29 \mathrm{ab}$ & 6.6 & 22.8 & 1059 & 1018 & 174.4 & 17.1 \\
\hline & $2011-12$ & 31 Jan. & 7 Mar. & 35 & & & & 827 & & & \\
\hline \multirow[t]{3}{*}{ Xiyeqing } & $2009-10$ & 24 Feb. & 1 Mar. & 8 & & & & 1400 & & & \\
\hline & 2010-11 & 18 Feb. & 7 Mar. & 17 & $20 \mathrm{a}$ & 13.7 & 68.5 & 1196 & 1179 & 230.3 & 19.5 \\
\hline & $2011-12$ & 5 Feb. & 12 Mar. & 35 & & & & 940 & & & \\
\hline \multirow[t]{3}{*}{ Fenghou } & 2009-10 & 8 Mar. & 19 Mar. & 17 & & & & 1635 & & & \\
\hline & $2010-11$ & 4 Mar. & 18 Mar. & 14 & $17 \mathrm{a}$ & 3.5 & 20.2 & 1870 & 1697 & 151.3 & 8.9 \\
\hline & $2011-12$ & 28 Feb. & 21 Mar. & 21 & & & & 1587 & & & \\
\hline \multirow[t]{3}{*}{ Yanhua } & 2009-10 & 8 Mar. & 17 Mar. & 9 & & & & 1156 & & & \\
\hline & 2010-11 & 25 Feb. & 13 Mar. & 16 & $16 \mathrm{a}$ & 6.5 & 41.4 & 1494 & 1250 & 213.1 & 17.1 \\
\hline & $2011-12$ & 21 Feb. & 15 Mar. & 22 & & & & 1100 & & & \\
\hline
\end{tabular}

zThe date of dormancy breaking and flowering $\left(\mathrm{F}_{50}\right)$ also presented in this table. The delta JD was calculated in this table.

${ }^{y}$ Within columns, different letters (a and b) indicate statistically significant differences among cultivars by Duncan's multiple range test at 5\% level.

$\mathrm{JD}=$ Julian days; GDH = growing degree-hours.

$R$ close to 0.98 . Therefore, we can classify the japanese apricot cultivars by flowering time. Our results showed a high correlation between chilling requirement and date of dormancy breaking, which agrees with the data of Campoy et al. (2012).

Heat requirements for flowering of japanese apricot cultivars. The results showed that the difference in heat requirements of different cultivars for flowering, and of the same cultivar in different years, was not significant. Many researchers had reported this phenomenon in almond [Prunus dulcis (Mill.) D.A. Webb] (Egea et al., 2003), apricot (Prunus armeniaca L.) (Ruiz et al., 2007), sweet cherry (Prunus avium L.) (Alburquerque et al., 2008), and pistachio (Pistacia vera L.) (Rahemi and Pakkish, 2009). The results obtained in apricot by Bailey et al. (1982) and Guerriero et al. (2002) did not show a correlation between chilling requirements and heat requirements. LinsleyNoakes and Allan (1994) and Egea et al. (2003) found no differences in heat requirements with different chilling requirements with nectarine and almond cultivars. Swartz and Powell (1981) observed in apple [Malus domestica (Borkh)] cultivars that chilling requirements were positively correlated with heat requirements for flowering. A high negative correlation between chilling requirements and heat requirements in peach (Prunus persica) was reported by Chen et al. (2012) and Pawasut et al. (2004), which indicated that heat requirement is dependent on the amount of chilling exposure with reduced heat requirement after a long chilling exposure. A low negative correlation between chilling requirements and heat requirements has been reported by many authors (Alburquerque et al., 2008; Campoy et al., 2012; Egea et al., 2003; Ruiz et al., 2007), but our results show a positive correlation between chilling requirements and heat requirements. These contradictory results may be explained by different climatic conditions, especially temperature.

Many researchers who studied the relations among chilling requirements, heat requirements, and flowering date obtained different results. An inverse relationship between the effects of chilling and heat requirements on the flowering date of peach cultivars was found (Citadin et al., 2001). Alonso et al. (2005) reported that heat requirements of almond were more important for regulation of flowering date than chilling requirements in the cold climatic conditions of Zaragoza (northeast Spain). However, in southeast Spain, the flowering date of some almond cultivars was influenced more by chilling than by heat requirements (Egea et al., 2003). Campoy et al. (2012) and Ruiz et al. (2007) reported similar results, which indicates that flowering date is only slightly influenced by heat requirements and that other factors are more important, especially chilling requirements. Our results support this limited relationship between flowering date and heat requirements, which indicates that other factors are responsible for variation of the flowering date.

Flowering date of japanese apricot cultivars. A wide range in the flowering date $\left(\mathrm{F}_{50}\right)$ from 5 Feb. to 21 Mar. was observed in all three years and was associated with the higher temperatures recorded. A low negative correlation between delta DJ and flowering date was reported by Campoy et al. (2012). However, our results showed a high negative correlation between delta DJ and flowering date and cultivars with lower chilling requirements showed earlier flowering dates. In our study, no significant differences were found between years with regard to the flowering dates; for example, 'Fenghou' flowered at approximately the same time in all three years. Many authors have reported no significant differences among heat requirements of cultivars, and flowering dates of cultivars, but a significant correlation was found between chilling requirement and flowering dates (Campoy et al., 2012; Egea et al., 2003; Ruiz et al., 2007). Our results suggested that the chilling requirement is the main factor determining the flowering date.

\section{Conclusions}

The dynamic model has a lower $\mathrm{CV}$ than the Utah and the Weinberger models in three successive studied years. As a result of its convincing theoretical framework and wide application, we recommend it to quantify chilling requirements of japanese apricot under warm climatic conditions such as in Nanjing. However, more complex and more accurate models are needed to open new avenues in better understanding the complex process of dormancy.

The range of chilling requirements of the cultivars studied was from 26.3 to 75.7 chilling portions, and the heat requirements varied from 1017.7 GDH to 1697.3 GDH. However, our results do not clarify whether the heat requirements for flowering are an intrinsic characteristic of the cultivar.

The results show a high positive correlation between chilling requirements and flowering date. The relationship between heat requirements and flowering date was also positive, although the correlation coefficient was quite low. A positive correlation was observed between chilling requirements for breaking of dormancy and heat requirements for flowering. In addition, there is a high negative correlation between chilling requirements and delta JD and a low negative correlation between heat requirements and delta JD. These parameters are very useful in agricultural productions and scientific researches. Therefore, further work is needed to estimate the chilling and heat requirements of more japanese apricot cultivars to complete our knowledge of the adaptability of this species to areas where its culture has not been traditional.

\section{Literature Cited}

Alburquerque, N., F. García-Montiel, A. Carrillo, and L. Burgos. 2008. Chilling and heat requirements of sweet cherry cultivars and the relationship between altitude and the probability 
of satisfying the chill requirements. Environ. Exp. Bot. 64:162-170.

Alonso, J.M., J.M. Ansón, M.T. Espiau, and R.S. Company. 2005. Determination of endodormancy break in almond flower buds by a correlation model using the average temperature of different day intervals and its application to the estimation of chill and heat requirements and blooming date. J. Amer. Soc. Hort. Sci. 130: 308-318.

Anderson, J.L., E.A. Richardson, and C.D. Kesner. 1986. Validation of chill unit and flower bud phenology models for 'Montmorency' sour cherry. Acta Hort. 184:71-78.

Baggiolini, M. 1952. Stade repères du pecher. Revue Romande d'Agriculture Vit. Arbor 4:29-35.

Bailey, K., S. Kotowski, and L. Hough. 1982. Estimate of chilling requirements of apricot selections. Acta Hort. 121:99-102.

Bartolini, S., G. Zanol, and R. Viti. 2006. The cold hardiness of flower buds in two apricot cultivars. Acta Hort. 701:141-145.

Campbell, R.K. and A.I. Sugano. 1975. Phenology of bud break in Douglas-fir related to provenance, photoperiod, chilling and flushing temperature. Bot. Gaz. 136:290-298.

Campoy, J.A., D. Ruiz, L. Allderman, N. Cook, and J. Egea. 2012. The fulfilment of chilling requirements and the adaptation of apricot (Prunus armeniaca L.) in warm winter climates: An approach in Murcia (Spain) and the Western Cape (South Africa). Eur. J. Agron. 37:43-55.

Campoy, J.A., D. Ruiz, and J. Egea. 2010. Effects of shading and thidiazuron + oil treatment on dormancy breaking, blooming and fruit set in apricot in a warm-winter climate. Sci. Hort. 125:203-210.

Campoy, J.A., D. Ruiz, and J. Egea. 2011. Dormancy in temperate fruit trees in a global warming context: A review. Sci. Hort. 130: 357-372.

Chen, M.Q., W.Q. Ye, Z.X. Liu, H.C. Zhong, X.B. Liu, and Z.M. Pan. 2012. The requirements of chilling for bud dormancy and caloric for blooming for 12 peach varieties. Scientia Silvae Sinicae 48:86-90.

Chu, M.Y. 1999. China fruit records-Mei. China Forestry Press, Beijing, China.

Citadin, L., M.C.B. Raseira, F.G. Herter, and J. Baptista da Silva. 2001. Heat requirement for blooming and leafing in peach. HortScience 36:303-307.

Couvillon, G.A. and A. Erez. 1985. Influence of prolonged exposure to chilling temperatures on bud break and heat requirement for bloom of several fruit species. J. Amer. Soc. Hort. Sci. 110:47-50.
Darbyshire, R., L. Webb, I. Goodwin, and S. Barlow. 2011. Winter chilling trends for deciduous fruit trees in Australia. Agr. For. Meteorol. 151:1074-1085.

Dennis, F.G. 2003. Problems in standardizing methods for evaluating the chilling requirements for the breaking of dormancy in buds of woody plants. HortScience 38:347-350.

Egea, J., E. Ortega, P. Martínez-Gómez, and F. Dicenta. 2003. Chilling and heat requirements of almond cultivars for flowering. Environ. Exp. Bot. 50:79-85.

Erez, A. 2000. Bud dormancy; phenomenon, problems and solutions in the tropics and subtropics, p. 17-48. In: Erez, A. (ed.). Temperate fruit crops in warm climates. Kluwer Academic Publishers, The Netherlands.

Erez, A., G.A. Couvillon, and C.H. Hendershott. 1979. The effect of cycle length on chilling negation by high temperatures in dormant peach leaf buds. J. Amer. Soc. Hort. Sci. 104: 573-576.

Fennell, A. 1999. Systems and approaches to studying dormancy: Introduction to the workshop. HortScience 34:1172-1173.

Fishman, S., A. Erez, and G.A. Couvillon. 1987a. The temperature dependence of dormancy breaking in plants: Mathematical analysis of a twostep model involving a cooperative transition. J. Theor. Biol. 124:473-483.

Fishman, S., A. Erez, and G.A. Couvillon. 1987 b. The temperature dependence of dormancy breaking in plants: Computer simulation of processes studied under controlled temperatures. J. Theor. Biol. 126:309-321.

Gariglio, N., D.E.G. Rossia, M. Mendow, C. Reig, and M. Agusti. 2006. Effect of artificial chilling on the depth of endodormancy and vegetative and flower budbreak of peach and nectarine cultivars using excised shoots. Sci. Hort. 108: 371-377.

Guerriero, R., R. Viti, P. Monteleone, and M. Gentili. 2002. La valutazione della dormienza nell'albicocco: Tre metodi a confronto. Frutticoltura 3:73-77.

Linsley-Noakes, G.C. and P. Allan. 1994. Comparison of two models for the prediction of rest completion in peaches. Sci. Hort. 59:107-113.

Luedeling, E. and P.H. Brown. 2011. A global analysis of the comparability of winter chill models for fruit and nut trees. Intl. J. Biometeorol. 55:411-421.

Luedeling, E., M.H. Zhang, and E.H. Girvetz. 2009a. Climatic changes lead to declining winter chill for fruit and nut trees in California during 1950-2099. PLoS ONE 4:E6166.
Luedeling, E., M.H. Zhang, V. Luedeling, and E.H. Girvetz. 2009b. Sensitivity of winter chill models for fruit and nut trees to climatic changes expected in California's Central Valley. Agr. Ecosyst. Environ. 133:23-31.

Luedeling, E., M.H. Zhang, G. McGranahan, and C. Leslie. 2009c. Validation of winter chill models using historic records of walnut phenology. Agr. For. Meteorol. 149:1854-1864.

Ou, S.K. and C.L. Chen. 2003. Apply Taiwan chilling model for estimating chilling requirement of local Mei trees. J. Beijing Forestry Univ. 25:6-10.

Pawasut, A., N. Fujishige, K. Yamane, Y. Yamaki, and H. Honjo. 2004. Relationships between chilling and heat requirement for flowering in ornamental peaches. J. Jpn. Soc. Hort. Sci. 73: 519-523.

Rahemi, M. and Z. Pakkish. 2009. Determination of chilling and heat requirements of pistachio (Pistacia vera L.) cultivars. Agr. Sci. China 8:803-807.

Richardson, E.A., S.D. Seeley, and D.R. Walker. 1974. A model for estimating the completion of rest for 'Redhaven' and 'Elberta' peach trees. HortScience 1:331-332.

Ruiz, D., J.A. Campoy, and J. Egea. 2007. Chilling and heat requirements of apricot cultivars for flowering. Environ. Exp. Bot. 61:254-263.

Shi, J.Y., J.Y. Gong, J.E. Liu, X.Q. Wu, and Y. Zhang. 2009. Antioxidant capacity of extract from edible flowers of Prunus mume in China and its active components. LWT-Food Science Technology 42:477-482.

Swartz, H.J. and L.E. Powell, Jr. 1981. The effect of long chilling requirement on time of bud break in apple. Acta Hort. 120:173-178.

Valentini, N., G. Me, R. Ferrero, and F. Spanna. 2001. Use of bioclimatic indexes to characterize phenological phases of apple varieties in northern Italy. Intl. J. Biometeorol. 45:191195.

Wang, X.Y., H.L. He, G.S. Liang, and C.X. Zhao. 2007. Study on the dormancy of mume cultivars in southern subtropical area of China. J. Fruit Sci. 24:308-312.

Weinberger, J.H. 1950. Chilling requirements of peach varieties. Proc. Amer. Soc. Hort. Sci. 56:122-128.

Yamane, H., Y. Kashiwa, E. Kakehi, K. Yonemori, H. Mori, and K. Hayashi. 2006. Differential expression of dehydrin in flower buds of two japanese apricot cultivars requiring different chilling requirements for bud break. Tree Physiol. 26:1559-1563. 